\title{
Linking Theory To Practice: Experiential Learning In An Employee Wellness Practicum
}

Sallie M. Scovill, Ph.D., University of Wisconsin - Stevens Point, USA Matthew D. Waite, Graduate Assistant, University of Wisconsin - Stevens Point, USA

\begin{abstract}
Engaging students in a process that connects real world experience with their course of study is well documented in the literature as a pedagogy linked with experiential learning. This paper is a case study of an experiential learning (EL) process in a practicum course in Employee Wellness. This case study describes how this unique program follows an EL model where students work together to manage an on-campus wellness programs for employees at the University of Wisconsin - Stevens Point.
\end{abstract}

Keywords: Experiential Learning; Employee Wellness Practicum

\section{INTRODUCTION}

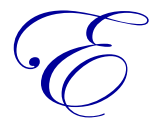

xperiential learning (EL) has been used extensively in higher education to provide students with handson learning experiences and to develop a deeper understanding of concepts associated with their major program of study (Nicholas, Baker-Sennett, McClanahan, \& Harwood, 2011; Govekar \& Rishi, 2007). This type of learning theory can be traced to Dewey (1927) who developed the notion of "Progressivism" where the student is the problem solver, and the teacher's role is more of a facilitator. The teacher creates opportunities for students to develop their problem-solving abilities by providing experiences that relate knowledge to immediate social needs. Hoover and Whitehead (1975) expand this definition stating, "Experiential learning exists when a personally responsible participant cognitively, affectively, and behaviorally processes knowledge, skills, and/or attitudes in a learning situation characterized by a high level of active involvement" (as cited in Gentry, 1990, p. 10). Experiential learning involves many formats including internships, practicum, field experiences, cooperative education, apprenticeships, or service learning (Kolb, 1984; Cantor, 1995; Linn, 1999; Lee, McGuiggan, \& Holland, 2010).

All experiential education opportunities have similar properties. First, the learning provides benefits to both the learner/provider and recipients (Peters, 2011). The process should help students learn and develop skills through active participation in a real world context where there is a practical application of academic content and theory (Greenberg, 1997; Peters, 2011; Prentice \& Garcia, 2000; Cantor, 1995). The experience should encourage critical-thinking and problem-solving skills by building on the curriculum and classroom activities (Prentice et al., 2000). In addition, Bringle (2003, as cited in Ball, 2008) emphasizes that active learning is a crucial part of the process, as is collaboration, feedback, practical applications, reflection, and cognition. All experiential education activities should be structured to meet a real need in the community or population served, to develop civic responsibility, or to provide career exploration (Mumford, Inumgu, \& Johnson, 2008).

The key to an experiential learning process is the active involvement of the students. The learner must be involved in shaping the process they will follow, guided not only by the concepts of the course, but also by their own personal knowledge and experiences (Bangs, 2011). To have a successful experiential leaning process, it is crucial to pay attention to the four phases of experiential learning - Design, Conduct, Evaluation, and Feedback (Wolfe and Byrne, 1975, as discussed in Gentry, 1990, p. 1). This interactive process is illustrated in Figure 1. This 
process-oriented model is similar to other experiential or service learning models described in the literature (Kolb, 1984; Mumford et al., 2008; Cantor, 1995; Gentry, 1990).

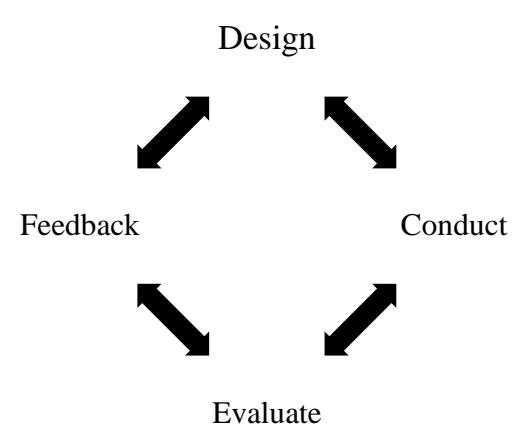

Figure 1

Process Oriented Version of the Wolf and Byrne Model. From "Research on Experiential Learning: Enhancing the Process," Adapted from Wolf and Byrne (1975) in Gentry, J.W. (1990). What is Experiential Learning? In J.W. Gentry, ed. Guide to Business Gaming and Experiential Learning, East Brunswick, Nichols/GP Publishing.

\section{CASE STUDY}

Wolfe and Byrne's four-phase methodology (as cited by Gentry, 1990) is incorporated in a practicum class at the University of Wisconsin - Stevens Point (UWSP). The School of Health Promotion and Human Development's major in Health Promotion/Wellness requires senior students to complete two 3-credit practicum courses. Students focused on corporate health promotion enroll in an Employee Wellness (EW) practicum as one of the optional courses. This course is unique from other practicum courses offered by UWSP or at other universities. Students in this course are in charge of and manage the university's employee wellness program, Pointers Achieving Wellness (PAWs). A literature and internet search of other university employee wellness programs did not find any other course similar to this where students are actually designing, creating, delivering, and evaluating programs offered to the organization's employees. With the exception of internship programs, there are few if any corporate wellness programs strictly managed by undergraduate students enrolled in practicum courses like the UWSP employee wellness program.

PAWs is a program designed to promote high-level wellness to all faculty/ staff at the university. Students in this practicum (EW) create, implement, and evaluate wellness programs geared toward interests and needs of employees. This practicum is a culminating experience designed to synthesize the knowledge from students' previous coursework. The Employee Wellness practicum programs touches on each of the seven dimensions of wellness: Social, Physical, Emotional, Career, Intellectual, Environmental, and Spiritual.

\section{Background of the employee wellness practicum}

UWSP employs around 1,200 full time faculty and staff and the wellness practicum is how all health promotion programming is delivered at the worksite. In place for over 12 years, in 2008, the course underwent a significant revision as the campus wellness committee developed and implemented a strategic plan for wellness. Goals from the plan are incorporated as part of the course objectives in the practicum. Students gain experience as pre-professionals in health promotion as a way to advance skill levels beyond basic competencies gained in lower level courses. Each semester, 12 students enroll in a three-credit class in an effort to develop and implement worksite wellness for university employees. Students supply faculty and staff with current health information to increase awareness of new health trends and offer employees opportunities to engage in making healthy lifestyle choices. Each semester the class documents their learning experiences, both planned and unplanned, in their reflection papers and in a portfolio. The EW practicum is a unique format that helps students and UWSP employees learn the importance of collaboration in health promotion and disease prevention activities designed to connect the health needs of employees to course objectives for students. 
Ash, Clayton, and Atkinson (2005, as cited in Peters, 2011) and Bringle, (2003, as cited in Ball, 2008) feel collaborative teaching and learning strategies are important in experiential or service learning courses. To enhance this process, students in the EW practicum also work in partnership with other academic disciplines, campus organizations, and community partners as a way to deliver programming to the campus. These opportunities have included working with instructors and students in Web and Media Design to develop a campus health risk assessment, and with Family and Consumer Science to provide family and relationship assessments. EW students created a recipe makeover contest in conjunction with Nutrition and Dietetics students and offered healthy cooking demonstrations. In addition, to develop a Stairway to Better Health program, freshman and sophomore students in Fine Arts created health-oriented art displayed in the main stairwell of the Learning Resource Center. Health Sciences students, EW practicum students, and health advocate students are currently working to develop a tobacco free campus initiative, and have met with the Student Government Association, Faculty Senate, and the Chancellors leadership team in order to solicit support for the policy. Students in other health promotion and wellness classes within the major have assisted with marketing projects, bulletin board development, personal training, and exercise testing for the PAWs program.

Students in the EW practicum have extended their collaborative projects to other campus organizations including the Environmental Health and Safety Department providing pre-work stretching programs for employee injury prevention and organizing the yearly Safety and Health Fair. EW students also work with Personnel and Benefits by staffing a booth at the benefits fair each October, and provide educational sessions on a variety of material to staff in other departments on campus. Students have provided screenings, education programs, health fairs, and fund raising for community organizations including Stevens Point Police Department, American Lung Association, Susan G. Komen Foundation, Ministry Health Care, and Del Monte Foods. The collaborative nature of the wellness course is an opportunity unequaled by many other programs within the university.

Each of the four phases of experiential learning is reviewed as they relate to the course in Employee Wellness at UWSP.

\section{Four phases of experiential learning}

\section{Design phase}

Bangs (2011, p. 30) states, "Design is the work done by the instructor before the course begins in order to set up the learning environment". This phase correlates with Gentry's (1990) theme that states a critical component of the design phase is the "experience must be Applied with the expected educational outcomes articulated and related to the curriculum" (p. 13). The EW instructor sets course objectives outlined in the syllabus. These objectives are then broken down using a backward design process into enduring understandings, knowledge, and skills (Wiggins \& McTighe, 2005). An example from the course is outlined in Figure 2.

Though employee wellness is a year round program, overseen by the instructor and a graduate assistant, the involvement of undergraduate students is constrained by the 16-week course calendar where students meet once a week. However, during summer semester, the class meets twice a week for eight-weeks. Each semester, students volunteer for, or develop projects or programs they are responsible for leading throughout the semester. The instructor identifies many projects and partners prior to class, but students bring ideas to class and if feasible, develop these into viable programs during the semester. Due to the evolving nature of wellness programs, new projects may be introduced throughout the semester as need arises. In addition to the selection of activities for participants, the instructor also addresses factors that may affect student learning. Students work collaboratively within the class or in conjunction with partners on campus to create their project timelines. Gentry (1990) feels that having the class be participative, interactive, and applied to real world activities are all critical factors in designing applied experiential learning activities. 


\section{Enduring Understandings:}

Students will understand that...

- Wellness should reach all employees who have varied needs, interests, capabilities, and opportunities.

- Wellness programs understand \& respect this fact and plan programs accordingly.

- Organization, strategic thinking, and planning skills are important to wellness program success.

- Challenges exist in engaging employees in health promoting behavior and creative solutions are necessary to respond to this conundrum.

- Health promotion needs are based on observed and obtained assessment data.

Knowledge (Know):

Students will/can...

- Demonstrate awareness of diverse needs of employees on campus through inclusive program activities.

- Recognize the boundaries of their professional competence and are accountable for their professional activities and actions.

Skills (Able to do):

- Become familiar with resources available to health promotion professionals

Students will/can...

- Demonstrate proficient writing skills by contributing an article to the EW newsletter.

- Capable of analysis and problem solving that will result in improving health outcomes.

- Apply the process of planning, implementing, and evaluating health promotion program through project plan files.

Dispositions (Value/Appreciate):

Students will/can...

- Demonstrate understanding for differences among individual's attitudes toward personal wellness through personal reflection. (Perception)

Assessment

- Display respect for employees' (Empathy)

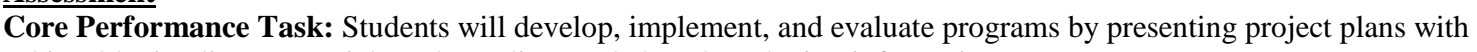
achievable timelines, materials and supplies needed, and marketing information.

Students will develop accurate and applicable evaluation tools for each activity they implement each semester and present results to class upon completion of each wellness program. The students will be able to present strengths and weaknesses of the program. Students should be able to evaluate process (implementation and delivery) and outcomes (impact) and understand the difference.

Figure 2: UWSP Employee Wellness Backward Design Course Objectives

\section{Conduct}

The second phase in the experiential learning process is conduct. That is, the instructor's process of monitoring the experience of the students and making any needed modifications to the design of the course (Bangs, 2011). This part of the phase should be structured and monitored by the instructor (Gentry, 1990). The EW course meets weekly during the semester at a regular time and follows a set agenda led by members of the class (See Figure 3). The class meeting time is structure to simulate a real world experience of how an employee wellness committee meeting would be held at a worksite. The agenda outlining the projects, responsibilities, and due date is distributed to the group in advance of the class meeting. Students also meet with the professor or graduate student for additional guidance as needed based on their project timeline. The EW practicum students are expected to meet in planning groups outside of class to work on the program(s) they are responsible for delivering to the UWSP campus.

\begin{tabular}{|l|l|l|l|l|}
\hline \multicolumn{1}{|c|}{ Project } & Assigned to & Actions in Progress & Due Date & Follow-up/Suggestions \\
\hline Group Exercise Class & & & & \\
\hline Newsletter & & & & \\
\hline
\end{tabular}

Figure 3: Sample Employee Wellness Agenda

Students are required to turn in project planning sheets prior to class, and are responsible for ensuring that fellow students deliver projects or materials as requested. Because so much work is done outside of class, some students do not participate at the same level as other students. This is revealed by their project planning sheets, work logs, and follow up process evaluation on program effectiveness by each student involved in that particular assignment. See Figure 4 for an example of the process planning sheet. These sheets are used by the instructor to 
make suggestions on improving programs, or to make any adjustments needed to ensure students stay on track throughout the semester.

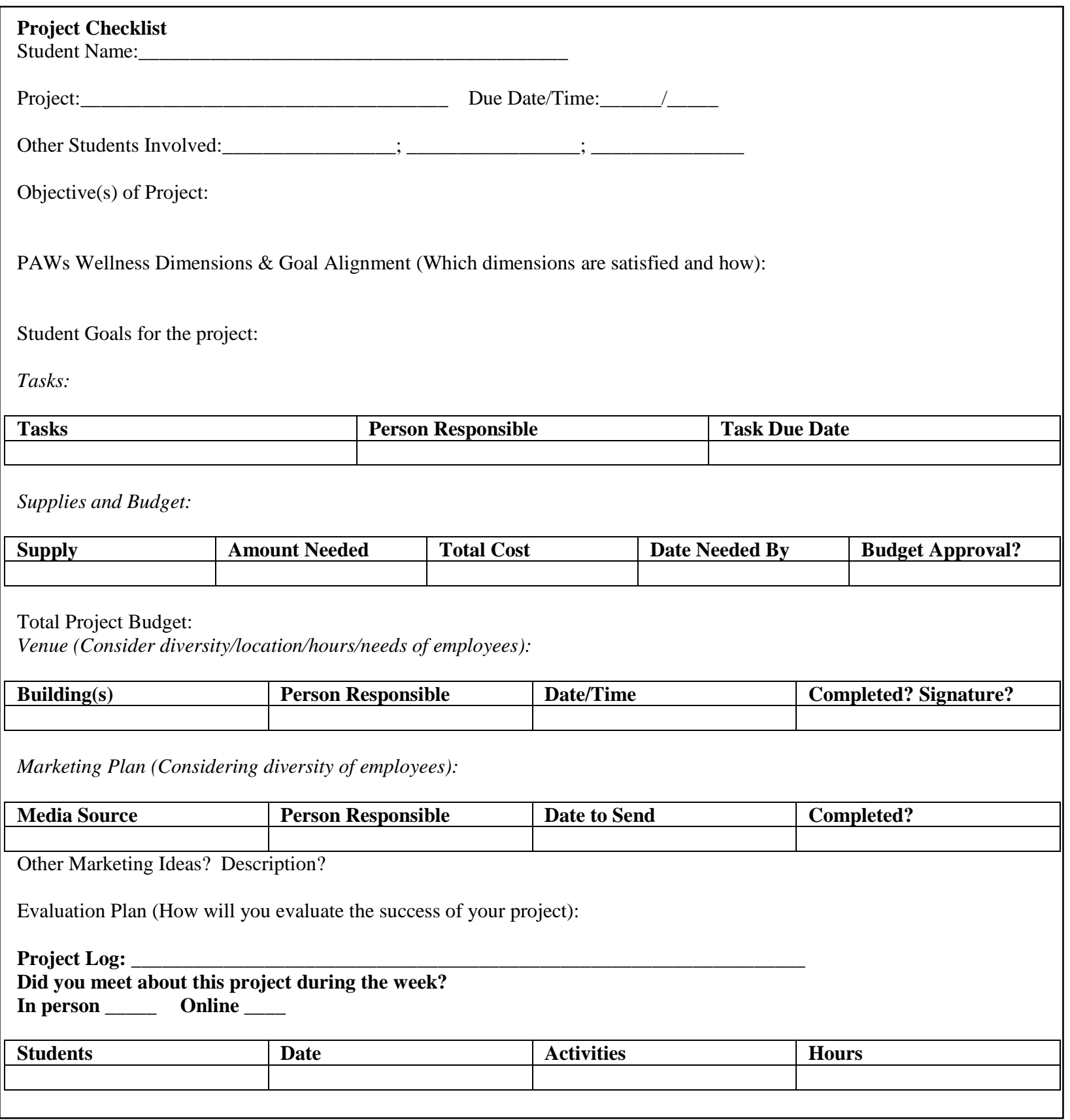

Figure 4: UWSP Employee Wellness Sample Project Planning Sheet

\section{Evaluation}

Cantor, (1995, Evaluating the effectiveness of experiential learning activities section, II 1) states, "Evaluation of experiential learning activities, much like any other application of evaluation, should be tied to specific experiential learning program objectives." There are several methods of evaluation present in the EW practicum. Utilizing a variety of methods ensures that students, instructor, and course objectives are consistently 
assessed before, during, and after completion of the course. These evaluation methods include both process and outcomes evaluation.

Process Evaluation. The Centers for Disease Control and Prevention (2010) defines process or implementation evaluation as a method to assess if a program has been implemented as intended, and why or why not. This format is achieved through the weekly presentation of student planning reports. The weekly class time also allows the professor, graduate student, and fellow classmates to comment and assist each project team with developing, and fine-tuning the delivery of their programs. At the conclusion of each program, students and the instructor debrief the process. Part of the learning process is allowing students to make mistakes. Bangs (2011, p. 32) states, "It is expected that mistakes will happen in experiential learning. Purposefully allowing students to make mistakes... can generate some of the strongest learning experiences, if the students have an opportunity to learn from the mistakes." The debriefing at the conclusion of each project along with the end of course reflection paper helps students identify what they could have done better, make suggestions for improving their process, and how the experiences aligned with the learning outcomes set for the course.

Outcome evaluation. The type of evaluation to determine whether a program is making progress on the short-term, intermediate, or long-term outcomes is known as effectiveness or outcomes evaluation (CDC, 2010). In the EW practicum, outcome evaluation is used to determine accomplishment of learning outcomes, meeting objectives of the PAWs strategic plan, and effectiveness of each individual program implemented during the semester. Attainment of learning objectives is measured qualitatively and quantitatively. Student portfolios, planning sheets, and reflection papers give students the opportunity to reflect and evaluate the learning they experienced during the course. Student time logs assist the instructor and graduate assistant in quantifying time students spend in project development. In addition to the students learning through evaluation, the instructor also receives valuable information about the course. One important tool is student class evaluations. Students showed favorable responses in class evaluations. The course consistently receives scores of $1.1-1.2$ (1.0 best score) and comments indicate that students enjoy the learning process of the practicum.

In the planning progress reports, students also need to reflect on the work they have done and develop procedures for measuring the success of the projects they implement throughout each semester. For most students in the EW practicum, this is an area where they need additional instruction. Students are graded on their ability to critically analyze through the evaluation process and the types of instruments they should use, not strictly on the quality of the procedures.

\section{Feedback}

The last phase in the EL progression is feedback. Bangs (2010, p. 32) states, "The instructor needs to continuously engage in developing the positive outcomes in the process and removing negative experiences." Because students will make mistakes in the process, using positive feedback as a learning tool is an important aspect in the process. It is important to note that the instructor needs to provide process feedback to balance and counteract the outcome feedback received (Gentry, 1990). EW students are continually reminded that they are not graded on their mistakes, but on the quality of their planning, and learning from the process of engaging in the projects.

Students, the EW instructor, and graduate assistant are all involved in giving feedback on the programs as well as participants in the employee wellness programs. Any communication received from faculty and staff is shared with students at each class meeting. Comprehensive employee surveys are conducted on campus to assess the PAWs program every two to three years. In 2009, employee surveys showed a positive attitude and encouraging responses regarding programs they participated in on campus. Feedback showed over $76 \%$ of employees were familiar with the PAWs program.

Other methods for obtaining feedback should help students reflect on the learning process, and assist the instructor in understanding how students have learned in the class. One method is utilizing personal reflection papers at the end of the semester. Reflection is routinely considered a critical component of experiential learning (Mumford et al., 2008; Bangs, 2011). At the end of each semester, students are able to review what they have learned, how they achieved course learning objectives, and reflect on their personal leadership process. 
Portfolios are an additional method of providing student feedback and are developed for life and workexperience evaluation (Cantor, 1995). The portfolio is an accumulation of all artifacts from not only the practicum, but as a way to combine relevant materials from other courses and outside experiences highlighting student's development as a professional. Artifacts, as defined by Merriam (2001), are written, visual, and physical materials that communicate relevant information to the study at hand. Examples of artifacts include the project planning sheets, calendars, worksheets, newsletters, program flyers, and pictures. Students are encouraged to use these portfolios during intern and job interviews. Feedback from several students indicate that this was helpful in demonstrating to potential employers skills developed while at the university.

\section{CONCLUSION}

Learning, according to Kolb's model of experiential learning is a circular process that does not end with the feedback stage (Kolb, 1984). Information obtained throughout the process from students, employees, and partners inform the instructor about changes that need to be made to the course. These changes can and do occur at any stage in the process. An internet search found few if any University employees wellness programs run solely by students without full time wellness staff. This experiential learning process benefits students and employees at UWSP and serves as a learning laboratory. Kolb believes "learning is the process whereby knowledge is created through the transformation of experience" (1984, p. 38). Therefore, Cantor describes the main outcome of EL experiences as "A need for educated workers and citizens who can meet the challenges of a new world economy and order" (1995, Experiential learning in higher education: A synthesis of successful practices section, II 1). Students completing the practicum at UWSP embody this concept and are well prepared for the next phase of their life journey.

\section{AUTHOR INFORMATION}

Sallie Scovill, Assistant Professor, School of Health Promotion and Human Development, joined the University of Wisconsin Stevens Point in fall 2007. She teaches a practicum in Employee Wellness and oversees pre-professional development of student interns. Her research interests include worksite health promotion and wellness in community and corporate organizations, and changes in student's self- efficacy from experiential learning. She consults with the maritime industry on merchant marine health and wellness. Her doctoral degree is from Middle Tennessee State University in Human Performance where she was awarded a doctoral fellowship. Previously she was corporate wellness coordinator at Vanderbilt University Medical Center. E-mail: sscovill@uwsp.edu (Corresponding author)

Matthew D. Waite is originally from Stevens Point, WI, but currently lives in Madison, WI. Matt attended UW Madison and received his bachelors of science in dietetics. After his undergrad, Matt spent his time working as a store manager of a Madison coffee shop and racing bicycles at the elite level. In August 2011, Matt enrolled in UWStevens Point's nutritional science Master's program. A Graduate Assistant under the supervision of Professor Sallie Scovill in the employee wellness program, Matt hopes to start his own wellness consulting practice after graduation. E-mail: Matthew.d.waite@uwsp.edu

\section{REFERENCES}

1. Ball, M.A. (2008). Practicums and Service Learning in LIS Education. Journal of Education for Library and Information Science, 49(1), 70 - 82.

2. Bangs, J. (2011). Experiential learning in an Organizational Leadership Program. Journal of College Teaching \& Learning. 8(10), 29 - 33.

3. Cantor, J. A. (1995). Experiential learning in higher education: Linking classroom and community. ASHEERIC Higher Education Report, 24(7), 1 - 102.

4. Centers for Disease Control and Prevention, (2010). Comprehensive Cancer Control Branch Program Evaluation Toolkit. National Center for Chronic Disease Prevention and Health Promotion Division of Cancer Prevention and Control. Retrieved January 23, 2011, from http://www.cdc.gov/cancer/ncccp/prog_eval_toolkit.htm.

5. Dewey, J. (1927). The Public and its Problems. Chicago, IL: Swallow Press, Inc. 
6. Gentry, J.W. (1990). What is Experiential Learning? In J.W. Gentry, ed. Guide to Business Gaming and Experiential Learning, East Brunswick, Nichols/GP Publishing.

7. Giordani, P. (2007). What makes a college internship program effective, National Association of Colleges and Employers' (NACE) Journal, 70(3), 37 - 38.

8. Govekar, M.A. \& Rishi, M. (2007). Service learning: Bringing real-world education into the b-school classroom. Journal of Education for Business, September/October, 3-10.

9. Greenberg, J.S. (1997). Service learning in health education. Journal of Health Education, 28(6), 345-349.

10. Kerka, S. (1989). Cooperative Education: Characteristics and effectiveness. ERIC Digest No. 91. Columbus, Ohio: ERIC Clearinghouse on Adult, Career, and Vocational Education.

11. Kolb, D.A. 1984. Experiential Learning: Experience as the Source of Learning and Development. Englewood Cliffs, N.J.; Prentice-Hall, Inc.

12. Lee, L. McGuiggan, R. \& Holland, B. (2010). Balancing student learning and commercial outcomes in the workplace. Higher Education Research \& Development, 29(5), 561-574.

13. Merriam, S. B. (2001). Qualitative research and case study applications in education (2nd ed.). San Francisco, CA: Jossey-Bass.

14. Mumford, V., Joseph N., Inumgu, J.N., Johnson, J.A. (2008). Service learning in Sport Management: A community health project. Sport Journal, 11(2), n.p.

15. Nicholas, T.M., Baker-Sennett, J., McClanahan, L.G, \& Harwood, A.M. (2011). Journal of Human Services, 31(1), $38-50$.

16. Peters, K.A. (2011). Including Service Learning in the Undergraduate Communication Sciences and Disorders Curriculum: Benefits, Challenges, and Strategies for Success. American Journal of Audiology, 20, S181-S196.

17. Prentice, M., \& Garcia, R. (2000). Service learning: The next generation in education. Community College Journal of Research and Practice, 24(1), 19-26.

18. Wiggins, G. \& McTighe, J. (2005). Understanding by Design. (2nd ed.).Alexandria, VA; Association for Supervision and Curriculum Development. 